\title{
Magnitude and extent of gambling disorder in the Mexican population
}

\author{
Jorge Ameth Villatoro Velázquez,' Esbehidy Resendiz Escobar,' Marycarmen Noemí Bustos Gamiño,' \\ Ailema Roxana Mujica Salazar, ${ }^{1}$ María Elena Medina-Mora Icaza, ${ }^{2}$ Vianey Cañas Martínez, Itzia Sayuri Soto \\ Hernández, 'Clara Fleiz Bautista, ${ }^{1}$ Martín Romero Martínez ${ }^{3}$
}

Dirección de Investigaciones Epidemiológicas y Psicosociales, Instituto Nacional de Psiquiatría Ramón de la Fuente Muñiz, Ciudad de México, México.

2 Dirección General, Instituto Nacional de Psiquiatría Ramón de la Fuente Muñiz, Ciudad de México, México.

${ }^{3}$ Centro de Investigación en Evaluación y Encuestas, Instituto Nacional de Salud Pública, Cuernavaca, Morelos, México.

\section{Correspondence:}

Jorge Ameth Villatoro Velázquez

Dirección de Investigaciones Epidemiológicas y Psicosociales, Instituto Nacional de Psiquiatría Ramón de la Fuente Muñiz.

Calz. México-Xochimilco 101, Col. San Lorenzo Huipulco, Del. Tlalpan, C.P. 14370, Ciudad de México, México.

Phone: 4160 - 5461

Email: javvrosh@outlook.com

Received: 21 May 2018

Accepted: 3 July 2018

Citation:

Villatoro, J. A., Resendiz, E., Bustos, M. N., Mujica, A. R., Medina-Mora, M E., Cañas, V., ... Romero, M. (2018). Magnitude and extent of gambling disorder in the Mexican population. Salud Mental, 41 (4), 157-167. doi: $10.17711 /$ SM.0185-3325.2018.024

\section{(c) (1) $\$$}

\begin{abstract}
Introduction. Gambling disorder is characterized by an uncontrollable need to gamble, lack of control over gambling, prioritizing gambling over other activities, and continuing to gamble despite the negative consequences this entails. Worldwide, between $.1 \%$ and $5 \%$ of people show signs of problem gambling and between $.1 \%$ and $2.2 \%$ present a positive result in gambling disorder criteria. Objective. To determine the extent of the problem of gambling disorder in Mexico and to identify and analyze the demographic groups in which it occurs. Method. ENCODAT 2016-2017 is a probabilistic, multi-stage survey with national and state representativeness. The sample comprises 56877 people who answered a standardized questionnaire that collects information on addictive substance use and other areas such as gambling disorder. Results. A total of $24.5 \%$ of the population aged 12 to 65 have played a betting game at lifetime. Men have higher statistically significant prevalences than women in nearly all types of gambling and in six of the nine symptoms of gambling disorder. In Mexico, .3\% of the target population meet the criteria for gambling disorder, with adolescents showing the highest percentage (.4\%). Discussion and conclusion. It is necessary to reinforce public policies for this issue that include the development of preventive actions targeting the adolescent and youth population in Mexico, and to ensure the adequate monitoring of authorized centers.
\end{abstract}

Keywords: Gambling disorder, survey, Mexico, betting types.

\section{RESUMEN}

Introducción. El juego patológico se caracteriza por la necesidad incontrolable de jugar, la falta de control sobre el juego, la prioridad de jugar sobre otras actividades y de continuar jugando a pesar de las consecuencias negativas. A nivel mundial, entre . $1 \%$ y el $5 \%$ de las personas muestra señales de juego problemático y del $.1 \%$ al $2.2 \%$ presenta un resultado positivo en los criterios de juego patológico. Objetivo. Conocer la extensión del problema del juego patológico en México e identificar y analizar los grupos demográficos en los que se presenta. Método. La ENCODAT 2016-2017 es una encuenta probabilística y polietápica con representatividad nacional y estatal. La muestra fue de 56877 personas, las cuales contestaron un cuestionario estandarizado que recaba información sobre consumo de sustancias adictivas y otras áreas como el juego patológico o ludopatía. Resultados. El $24.5 \%$ de la población de 12 a 65 años ha jugado algún juego de azar alguna vez en la vida. Los hombres presentan prevalencias estadísticamente significativas más altas que las mujeres en casi todos los tipos de juegos y en 6 de los 9 síntomas de juego patológico. En el país, el $.3 \%$ de la población objetivo cumple con los criterios para juego patológico, y los adolescentes muestran el mayor porcentaje (.4\%). Discusión y conclusión. Es necesario reforzar políticas públicas sobre el tema que incluyan el desarrollo de acciones preventivas dirigidas a la población adolescente y joven del país, así como incidir en el monitoreo adecuado de los centros autorizados.

Palabras clave: Juego patológico, encuesta, México, tipos de apuesta. 


\section{INTRODUCTION}

Gambling disorder was acknowledged as a problem in 1992. The World Health Organization took the diagnostic criteria from the International Statistical Classification of Diseases and Related Health Problems ICD-10 and defined them as frequent, repeated episodes of betting that dominate the patient's life, leading them to ignore social, occupational, material, and familial aspects (World Health Organization, 2004). More recently, in the initial version of the ICD11 , it was indicated that gambling disorder is characterized by a pattern of persistent or recurrent gambling behavior that may be online (in other words, through the Internet) or offline, and that the individual has no control over it, prioritizes it over other activities and continues to engage in it despite the negative consequences it entails. The first diagnostic criteria for gambling disorder were presented in the Diagnostic and Statistical Manual DSM-III (American Psychiatric Association, 1980), classified within impulse control disorders. The DSM-5 (American Psychiatric Association, 2014) currently classifies it in the section of substance-related disorders and indicates that it is a recurrent, persistent dysfunctional gambling behavior that interrupts personal, family or work activities. It also recognizes it as a continuous problem according to the specificity of the gravity of the problem (mild, moderate, or severe) and in accordance with the established criteria (4-5 criteria, 6-7, and 8-9 criteria, respectively).

Moreover, Cruz et al. (2010) indicate that it is a behavioral alteration that occurs progressively and is characterized by an uncontrollable need to gamble regardless of the negative consequences it entails. For his part, Potenza (2008) says that the gambler risks something of value with the hope of obtaining something more valuable.

There are also other categories related to the type of gambler that are established according to the degree of interest and involvement in gambling. On the one hand, there is the social gambler, who only participates and bets to have a good time in accordance with his financial possibilities and is able to stop gambling when he decides to do so. There is also the professional gambler, who gambles on moves in which he has calculated that he has a possibility of winning, since this is his sole purpose. Conversely, the problem gambler has only minimal control over his gambling and the amounts of money he bets affect his economy (Santos, 2008).

\section{The magnitude of the problem}

An analysis of the extent of this problem shows that Europe is the place with the greatest interest in gambling disorder as a health concern. Data from UK indicate that in 2017, $45 \%$ of people aged 16 and over ( $48 \%$ men and $41 \%$ women) had participated in at least one form of gambling in the past four weeks; $.8 \%$ of the people were identified as problem gamblers according to the Problem Gambling Severity Index (PGSI), while 3.9\% identified themselves as low or moderate risk gamblers according to the criteria of the DSM-IV (Gambling Commission, 2018). However, prevalence studies have used different measuring instruments, each with its own classification criteria, such as the South Oaks Gambling Screen (SOGS), the Problem Gambling Severity Index (PGSI), the American Psychiatric Association's Diagnostic Criteria for Pathological Gambling (DSM-IV), the Diagnostic Interview Schedule for Pathological Gambling (DIS), the Diagnostic Interview for Gambling Severity (DIGS), the National Opinion Research Center DSM Screen for Gambling Problems (NODS), Gamblers Anonymous Twenty Questions (GA20), and the Lie/Bet scale. Readers are recommended to consult the original studies to see the evaluation criteria for each scale.

In Norway, for instance, it was found that $67.9 \%$ of people between the ages of 16 and 74 had participated in betting game in the past year, . $7 \%$ of which were problem gamblers (Bakken, Götestam, Gråwe, Wenzel, \& Øren, 2009), whereas in the Netherlands, the percentage of problem gamblers was .2\% in 2005 and 2011, while that of atrisk gamblers was .4\% in 2005 and .7\% in 2011 (Goudriaan, 2013).

On the Americas, a study conducted in Brazil with 3007 respondents indicated that $1.3 \%$ were classified as problem gamblers and the same percentage with gambling disorder, according to the DSM-IV criteria (Tavares et al., 2010).

Calado and Griffiths (2016) also reviewed 69 studies from different parts of the world in the general population and found variations in annual prevalence ranging from $.1 \%$ to $5 \%$ of people who met the diagnostic criteria for problem gambling, the United States (5\%), Hong Kong, and Finland (4\% each) being the countries with the highest prevalence, compared with Switzerland (.1\%) and Spain (.2\%), where lower prevalences were found. The percentages of the population that met the criteria for gambling disorder were between . $1 \%$ and $2.2 \%$, with the highest prevalences being found in Hong Kong (2.2\%) and Macao $(1.8 \%)$ and the lowest in Denmark (.1\%), while countries such as Germany, UK, and Norway had a prevalence of . $2 \%$ each.

Although percentages for gambling disorder were higher in the adult population, several studies show the importance of attending the young population in view of their growing interest in gambling. For example, a study conducted in Canada (Huang \& Boyer, 2007) with 5666 young people ages 15 to 24 , revealed that $61.3 \%$ had bet in the previous 12 months, while $2.2 \%$ (3.3\% men and $1.1 \%$ women) showed moderate or problem risk. In UK, out of 8958 adolescents between the ages of 11 and 15 years, $28.2 \%$ of boys and $12.7 \%$ of girls reported having partici- 
pated in betting game in the previous seven days (Forrest \& McHale, 2012). Lastly, in Chile, university students found that $10.5 \%$ of respondents could be classified as potential gamblers according to the DSM-IV-TR and DSM-5 criteria (Giacaman, Ñancupil, \& Jobet, 2015).

Although these studies highlight the problem of gambling disorder, comparability between them is difficult because they have heterogeneous samples and the instruments used are different and their comparability has not been proven.

\section{Factors and consequences related to gambling disorder}

At the same time, although it is a recently studied phenomenon, the literature has reported some of the factors that may be associated with gambling disorder, including demographic ones such as sex, age, marital status, and educational attainment. A study conducted in the city of Tegucigalpa showed that those who frequented gambling places were mostly men, aged between 20 and 29, single, who had completed middle school, and had permanent employment (Cruz et al., 2010). Among university students in Italy, it was found that men are more likely to engage in these activities (Sarti \& Triventi, 2017). In the United States, a study showed that men have more than twice as many gambling problems as women, that people between the ages of 31 and 40 are at the greatest risk, which decreases among the elderly, and that people with middle school education or less have approximately three times as many gambling problems as those with college or higher education (Welte, Barnes, Tidwell, \& Wieczorek, 2017). Additionally, in samples obtained from people seeking treatment for gambling problems, it has been found that the higher the age of onset of gambling, the lower the severity of this behavior (Angulo, 2014).

As for psychological factors, a study conducted on participants with problems with gambling behavior found that these people have difficulties initiating affective relationships and that they present affective instability, introversion, insecurity about expressing feelings, and emotional dependence (Castaño, Calderón, \& Restrepo, 2016). It has also been found that gambling disorder is associated with the presence of obsessive-compulsive disorder, anxiety, and depression (Hodgins et al., 2012).

Meanwhile, another study indicates that among middle-aged women (ages 30 to 59), high levels of stress and the use of negative coping strategies increase the likelihood of problem gambling (Afifi, Cox, Martens, Sareen, \& Enns, 2010).

As for interpersonal factors, it has been found that the approval of betting game by family and friends, having relatives or friends with a history of gambling disorder (Hanss et al., 2015), a poor relationship between one's parents, as well as a poor relationship between parents and offspring, substance abuse or gambling by parents, and a bad financial situation (Dominguez, 2009; Hodgins et al., 2012) constitute risk factors for gambling disorder, whereas in those who perceive a high degree of family integration, there is less likelihood of engaging in betting game (Arcaya, Martina, Gutiérrez, \& Romero, 2012).

As for the socio-environmental factors related to the availability of gambling and places for gambling, it has been found that the increase in gambling disorder is related to the availability of casinos, slot machines, and gambling halls (Castaño et al., 2016). In the particular case of Mexico, as of May 2018, the Secretaría de Gobernación (2018) had registered in the General Directorate of Games and Draws only 33 permit holders of number draws and betting centers (casinos), representing a total of 326 establishments in operation nationwide.

At the same time, gambling disorder has a significant impact on both gamblers and their relatives and close friends. Browne et al. (2016) states that the damage caused to gamblers and relatives occurs in eight areas: 1. financial damage, such as the reduction or loss of the ability to purchase essential items for the household; 2. relational conflicts, such as the lack of availability to spend time with one's partner and offspring; 3. emotional or psychological distress (anguish, shame, self-esteem problems, etc.); 4. poor health (little self-care as regards nutrition, hygiene, sleep, etc.); 5. cultural damage (low participation in cultural events and practices, etc.); 6. decrease in work or school performance; 7. criminal activity (presence of theft, fraud, etc.); and 8 . life course, such as the loss of primary relationships and social connection.

As far as Mexico is concerned, research on gambling disorder is still scarce. We find reviews and suggestions for its monitoring (Ortega, Vázquez, \& Reidl, 2009; Comisión Nacional contra las Adicciones, 2012), but there is undoubtedly a need to increase research on the subject. Having epidemiological studies and factors associated with gambling disorder will contribute to decision-making on public policies aimed at the prevention and attention of those who present this problem.

Although significant progress has obviously been made in the area, many elements remain to be researched and homogenized in the study of gambling disorder (analysis of comparable probabilistic samples; use of similar, standardized instruments; research on effective responses to the problem, etc.).

Given this situation, the present study, based on a national probabilistic sample and a reliable instrument derived from the symptoms defined in the DSM-5, seeks to answer the following questions in relation to the sociodemographic variables of socioeconomic index, age, and sex in the Mexican population: What are the most common betting types in the population? What is the magnitude and extent of 
gambling disorder and its symptoms? What types of bet are most closely related to the presence of gambling disorder?

\section{METHOD}

The results reported in this paper form part of the Encuesta Nacional de Consumo de Drogas, Alcohol y Tabaco (ENCODAT) 2016-2017, undertaken on population ages 12 to 65 in urban and rural communities. For more information on the study method, see the original documents (Villatoro et al., 2017).

\section{Population and sample}

The survey has a probabilistic, multistage and stratified design. The universe selected for the primary sampling units (PSU) comprises the aggregate of the AGEBs (Basic Geo-statistical Areas). A sample size of approximately 1 600 individuals per state was chosen. In each household, whenever possible, an adult ages 18 to 65 and a teenager ages 12 to 17 were selected through simple random sampling in each age group. A total response rate (home + individual) of $73.6 \%$ was obtained. The final sample obtained was 56877 complete interviews (23 820 men and 33057 women), where 12436 were adolescents and 44441 adults.

\section{Definition of variables}

\section{Gambling disorder}

Recurrent, persistent dysfunctional gambling behavior that causes clinically significant deterioration or discomfort and is manifested when the individual has presented four or more symptoms within the past 12 months, according to the DSM-5 criteria.

\section{Betting types for money}

This refers to forms of gambling such as cards, horse or dog racing, cockfights, sports, casinos, etc., on which the individual has bet money or valuable belongings.

\section{Socioeconomic index}

Indicator using information about the possession of goods (own house, car, computer, DVD, and microwave oven) and access to services (Internet, cable TV, and telephone), comprising five levels: low, lower middle, middle, upper middle, and high (Díaz-Acosta, Shiba-Matsumoto, \& Gutiérrez, 2015).

Age

Three age groups were established, from 12 to 17,18 to 29 , and 30 to 65 years old, the first two being designed to maintain the definition of youth established by the Instituto Mexicano de la Juventud (IMJUVE). For the purposes of this study, no further age groups were disaggregated, due to the low prevalence of the variable of interest.

\section{Community}

Rural (localities with fewer than 2500 inhabitants); urban (localities with 2500 or more inhabitants).

\section{Instruments}

The individual questionnaire was applied to the randomly selected individual, aged between 12 and 17 or 18 and 65 at the time of the visit. It collected data on sociodemographic information; tobacco, alcohol, and medical or illegal drug use; problems related to substance use, and personal, social and interpersonal aspects.

The gambling disorder scale comprises two sections. In the first, various betting types were measured, involving money or valuable belongings, which included the following indicators: 1 . Have you bet when playing cards? 2 . Have you bet on horse or dog racing, cockfights or other animals (at a racetrack, track, or with a bookmaker)? 3. Have you bet on sports (with the pools or with a bookmaker)? 4. Have you played dice for money? 5. Have you bet in a casino (whether authorized or not)? 6. Have you played the Lottery, Melate, or Tris? 7. Have you played bingo or traditional lottery for money? 8. Have you played on betting machines or slot machines (electronic, mechanical, or a combination of both)? 9. Have you bet when you have played bowling, billiards, golf, or other skill games? 10. Have you purchased instant raffle tickets such as Scratch Cards, etc.? 11. How often have you gone online to bet money? and 12. Other. Each one was measured according to whether or not the respondent had engaged in these behaviors, with a standardized Cronbach's Alpha of .76 for the scale. Moreover, the following question was asked in order to determine who they prefer to gamble with when they bet: When you play (cards/bingo/lottery/in slot machines), who do you prefer to do so with? With answer options $1=$ Friends; $2=$ Partner (husband/wife/boy/girlfriend); $3=$ Relatives; $4=$ Acquaintances; $5=$ Strangers; $6=$ Alone. Likewise, in order to determine the times when they usually bet, they were asked: When do you usually bet? The options were mornings, afternoons, nights, early mornings and all day; for these options, the answers were $1=$ Yes and $2=$ No.

The second section of this scale involved evaluating gambling disorder based on the DSM-5 indicators, which are as follows: 1. Your mind is often on betting (for example, you continually relive the experiences of past bets, condition, or plan your next bet, think of ways to get money to bet); 2. You feel the need to bet increasingly large amounts of money to obtain the desired excitement; 3 . You feel nervous or irritated when you try to reduce or stop gambling; 4. You often bet when you feel uneasy (for example, helpless, guilty, anxious, or depressed); 5. After losing money 
betting, you usually go back another day to try to win (to "recoup" your losses); 6. You lie to cover up your degree of involvement in gambling; 7. You have made repeated efforts to control, reduce, or stop gambling, always without success; 8. You have compromised or lost an important relationship, job, or academic or professional career due gambling; 9 . You rely on others to give you money to relieve your desperate financial situation caused by gambling. All symptoms were answered as present/absent. Although the scale makes it possible to measure severity levels according to the number of symptoms that occur from four onwards (mild = 4 to 5 , moderate $=6$ to 7 , and severe $=8$ to 9 ), given the low prevalence of the phenomenon, in this study, symptoms were only measured as present or absent according to the criteria of four or more symptoms. This scale has a Cronbach's Alpha value of .72 .

\section{Procedure}

In May 2016, a group of 323 interviewers, supervisors, cartographers, computer assistants, and coordinators were trained. The information was collected from June 1 to October 30,2016 . To this end, the cartographers paid an initial visit to selected blocks and localities to draw maps and make lists of dwellings to make the probabilistic selection of dwellings and identify risk areas. The interviewers applied the household questionnaire in the selected dwellings and once this stage had been completed, the computer application selected an adult and/or adolescent to apply the individual questionnaire. The supervisors verified each one of the non-response codes in the selected dwellings and among the selected household members. For each selected dwelling, at least four visits were scheduled at different times and on different days, including weekends, to increase the likelihood of finding the occupants. Field operating personnel were organized into eight routes, with each one consisting of a coordinator, two computer assistants, seven supervisors, and four interviewers per supervisor.

\section{Ethical considerations}

The survey was approved by the Research and Ethics Committees of the Instituto Nacional de Salud Pública (INSP) and the Instituto Nacional de Psiquiatría Ramón de la Fuente Muñiz (INPRFM). All the participants read a letter of informed consent and information was subsequently gathered on those who agreed to participate. In the case of minors, parents or guardians were asked for their authorization for their children to participate and if they agreed, they signed a letter of consent; minors' consent to participate in the study was also sought. In both cases, emphasis was placed on the objectives of the survey, the voluntary nature of participation, and the confidentiality of information.

\section{Statistical analysis}

The STATA 13 statistical program was used for the analyses, in each of which the sample design of the study was modeled. Estimates were obtained of the prevalence of each betting types, symptom of gambling disorder, and indicator of gambling disorder. Moreover, in order to analyze differences in the prevalence of these indicators between the different groups defined by demographic variables (sex, age, and socioeconomic index, using the community as a control variable in each model), adjusted prevalence rates $(P R)$ were estimated based on generalized linear models (GLMs) with log link and binomial distribution. For GLMs, standard errors, and 95\% confidence intervals (CI) were estimated. Additionally, in the analysis of the relationship between the type of game with bets and gambling disorder, $\chi^{2}$ was used.

\section{RESULTS}

\section{Betting types games preferred by the population}

Nationwide, $24.5 \%$ of the population aged 12 to 65 have ever bet for money (men 32\%, women 17.4\%). By age group, young people aged 12 to 17 years have the highest prevalence (35.3\%) compared with adults ages 18 to 29 $(28.6 \%)$ and 30 to 65 years $(18.8 \%)$.

Betting machines or slot machines are the most frequent form of gambling (11.8\%), followed by the Lottery/ Melate/Tris $(8.3 \%)$ and cards $(7.3 \%)$. Online gambling $(.8 \%)$, dice $(1.8 \%)$ and gambling in casinos $(2.5 \%)$ have the lowest prevalences.

In the analysis with the prevalence ratio $(P R)$ adjusted by community (Table 1), it was found that men play significantly more than women on betting machines or slot machines $(P R=1.77,95 \% \mathrm{CI}[1.64,1.92])$, and that the higher the socioeconomic index, the higher the prevalence ratio for playing on them (Lower middle: $P R=1.20 ; 95 \%$ CI [1.07, 1.35]; Middle: $P R=1.30 ; 95 \%$ CI $[1.15,1.47]$; Upper middle: $P R=1.44 ; 95 \%$ CI $[1.27,1.64]$; High: $P R=1.46 ; 95 \%$ CI $[1.27,1.69])$. By age, people ages 18 or older are less involved in this type of gambling than those ages 12 to 17 (18 to 29 years old: $P R=.61 ; 95 \%$ CI $[.56, .67] ; 30$ to 65 years old: $P R=.17 ; 95 \% \mathrm{CI}[.15, .19])$.

Among those who play Lottery/Melate/Tris, men are more likely to do so than women $(P R=1.75,95 \% \mathrm{CI}[1.54$ $1.99])$, as well as the population with a high socioeconomic index. In the category of cards, the risk of gambling is higher among men, as well as among those aged between 30 and 65 and those with a high socioeconomic index.

Although the remaining types of gambling (horse racing, sports, dice, casino, bingo or lottery, skill games, in- 


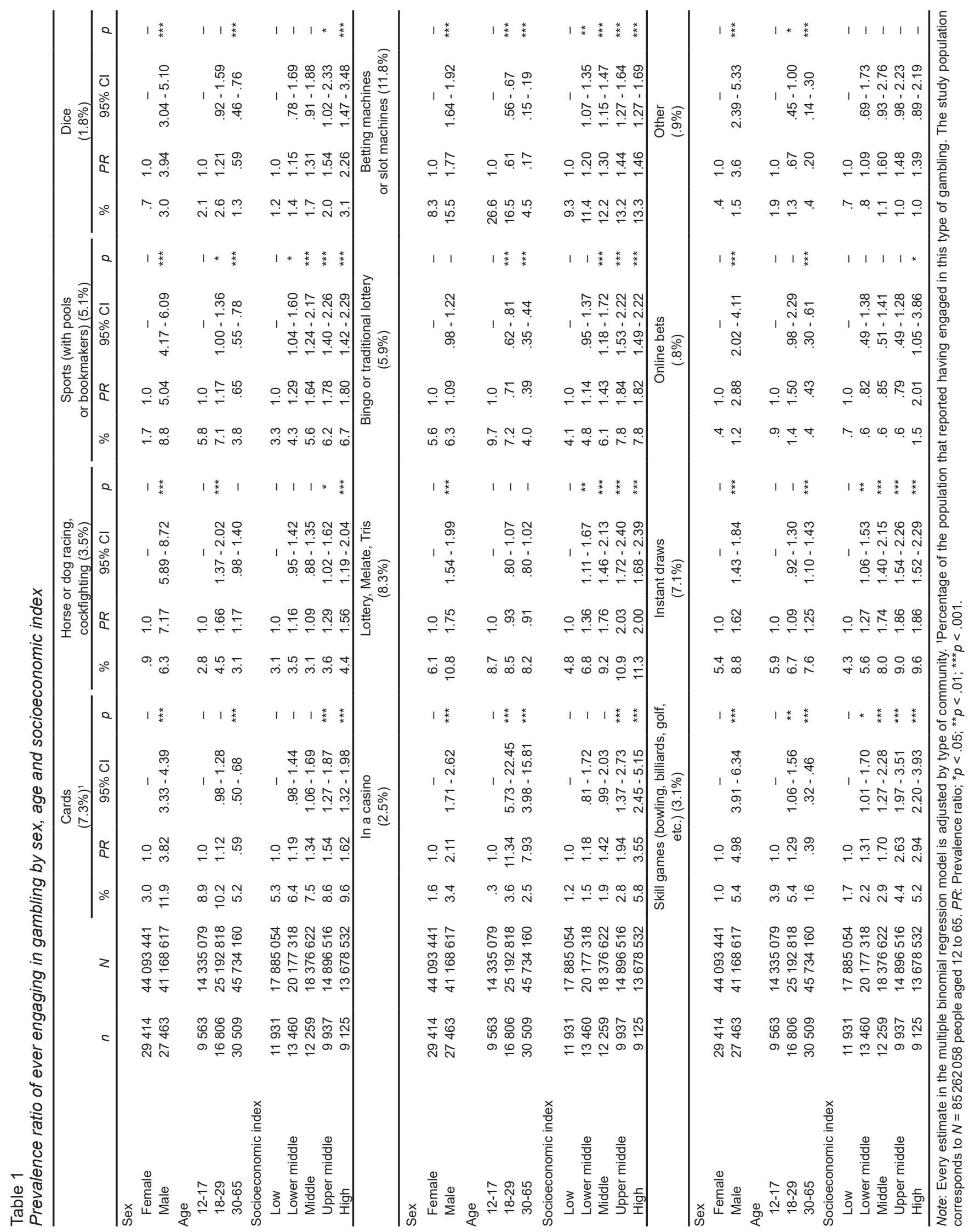




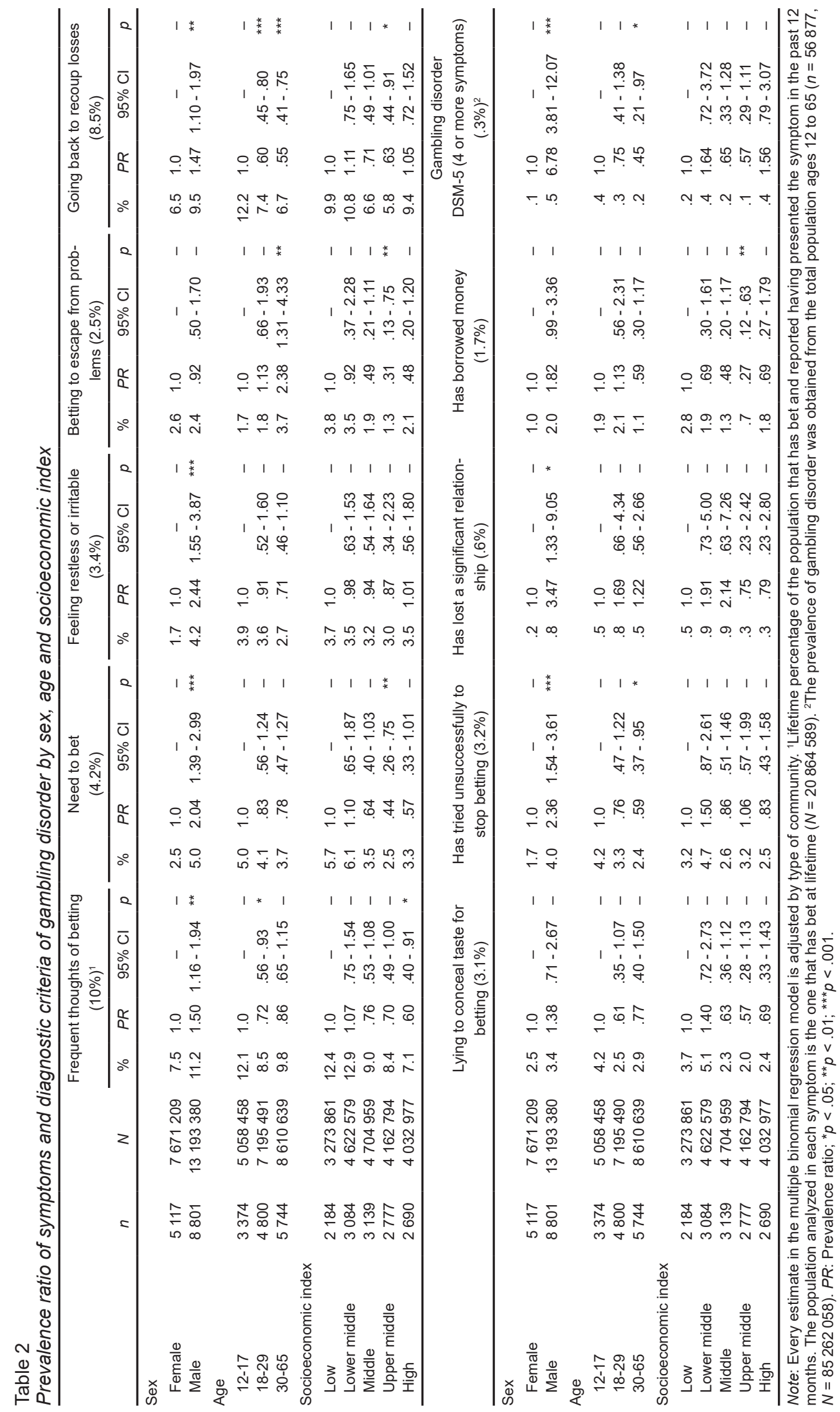


Table 3

Proportion of gambling disorder by type of bet

\begin{tabular}{|c|c|c|c|c|c|c|c|c|}
\hline \multirow[b]{2}{*}{ Type of bet } & \multicolumn{3}{|c|}{ Has not bet } & \multicolumn{3}{|c|}{ Has bet } & \multirow[b]{2}{*}{$\chi^{2}$} & \multirow[b]{2}{*}{$p$} \\
\hline & $n$ & $N$ & $\%$ & $n$ & $N$ & $\%$ & & \\
\hline Cards & 70 & 101541 & .7 & 91 & 134771 & 2.2 & 228.4 & *** \\
\hline Horse or dog racing, cockfighting & 99 & 120788 & .7 & 62 & 115525 & 3.9 & 643.1 & *** \\
\hline Sports (with pools or bookmakers) & 110 & 151060 & .9 & 51 & 85252 & 2.0 & 91.9 & * \\
\hline Dice & 121 & 183796 & 1.0 & 40 & 52517 & 3.4 & 209.7 & *** \\
\hline In a casino & 125 & 176231 & .9 & 36 & 60081 & 2.9 & 169.9 & ** \\
\hline Lottery, Melate, Tris & 87 & 100737 & .7 & 74 & 135575 & 1.9 & 157.7 & ** \\
\hline Bingo or traditional lottery & 97 & 153660 & 1.0 & 64 & 82652 & 1.6 & 41.3 & .084 \\
\hline Betting machines or slot machines & 50 & 80217 & .7 & 111 & 156095 & 1.6 & 84.3 & * \\
\hline Skill games (bowling, billiards, golf) & 105 & 139806 & .8 & 56 & 96506 & 3.6 & 463.9 & *** \\
\hline Instant draws & 112 & 130005 & .9 & 49 & 106307 & 1.8 & 82.4 & * \\
\hline Online & 144 & 209874 & 1.0 & 17 & 26439 & 4.0 & 135.7 & *** \\
\hline Other & 137 & 208290 & 1.0 & 23 & 22671 & 2.9 & 65.7 & $* *$ \\
\hline
\end{tabular}

Note: The population analyzed is one that has bet at lifetime $(N=20864589, n=13115)$. Population with gambling disorder $N=236313$.

${ }^{*} p<.05 ;{ }^{* *} p<.01 ;{ }^{* * *} p<.001$.

stant draws, and online betting) have a lower prevalence in the population, in the models analyzed, men also have significantly higher prevalence rates than women, with the exception of bingo or lottery, where men and women have a similar prevalence.

\section{Magnitude of gambling disorder and its symptoms}

Regarding the population that has bet money or valuable belongings, it was found that having frequent thoughts of betting (10\%), going back to recoup losses $(8.5 \%)$, and the need to gamble $(4.2 \%)$ are the most frequent symptoms of gambling disorder, while those with a lower prevalence include losing a significant relationship (.6\%), borrowing money $(1.7 \%)$, and betting to escape problems $(2.5 \%)$.

Likewise, the prevalence ratio analysis of the results of this section shows that men have a higher rate than women in six of the nine symptoms of gambling disorder. Losing a significant relationship, feeling restless or irritable, and trying unsuccessfully to quit gambling were the symptoms with the highest prevalence ratios. By age group, taking the 12 to 17 year age group as a reference, young people ages 18 to 29 have a lower proportion of frequent thoughts of betting and less intention of returning to recoup their losses. At the same time, those ages 30 to 65 years also showed less of a desire to recoup their losses and less difficulty quitting betting than adolescents, in addition to having a higher prevalence in the symptom of betting to escape problems. Lastly, those with an upper middle socioeconomic index presented significantly fewer gambling symptoms than those with a low socioeconomic index, particularly as regards the need to bet, betting to escape problems, going back to recoup losses, and borrowing money to continue gambling (Table 2).
Regarding the presence of gambling disorder, .3\% of the population presents four or more symptoms, which is significantly higher in men $(.5 \%)$ than in women $(.1 \%)$ $(P R=6.78,95 \%$ CI $[3.81,12.07])$. By age group, adolescents had the highest prevalence of gambling disorder (.4\%), significantly higher than the group ages 30 to 65 $(.2 \%, P R=.45,95 \%$ CI $[.21, .97])$ (Table 2$)$.

\section{Betting types with the highest proportion of gambling disorders}

Among the population that has ever bet, the study analyzed which betting types are related to the presence of gambling disorder. It was found that the highest percentages of gambling disorder were gambling online (4\%), betting on horse or dog racing, cockfights $(3.9 \%)$, and betting on skill games $(3.6 \%)$, while betting on betting machines or slot machines $(1.6 \%)$, immediate draws $(1.8 \%)$, and playing sports (pools or bookmakers) $(2 \%)$ have the lowest percentages (Table 3 ).

As for the preferred times for playing, the highest percentage of gambling disorder corresponds to those who gamble all day $\left(3.8 \%, \chi^{2}=62.1, p=.009\right)$. Moreover, the analysis of who they prefer to gamble with shows that the highest percentage do so with strangers (3.7\%) (Table 4).

\section{DISCUSSION AND CONCLUSION}

\section{Betting types}

The results of this study showed that the main betting games are betting machines or slot machines, the Lottery/Melate/ Tris, and card games. Slot machines obtained a prevalence of $11.8 \%$ among the population, with adolescents showing 
Table 4

Gambling preferences and gambling disorder

\begin{tabular}{|c|c|c|c|c|c|c|c|c|}
\hline & \multicolumn{3}{|c|}{ Does not prefer that schedule } & \multicolumn{3}{|c|}{ Prefers that schedule } & \multirow[b]{2}{*}{$\chi^{2}$} & \multirow[b]{2}{*}{$p$} \\
\hline & $n$ & $N$ & $\%$ & $n$ & $N$ & $\%$ & & \\
\hline \multicolumn{9}{|l|}{ Preferred gambling times $^{1}$} \\
\hline Mornings & 143 & 199974 & 1.1 & 18 & 36339 & 1.7 & 20.0 & .253 \\
\hline Afternoons & 72 & 103270 & 1.3 & 89 & 133043 & 1.0 & 12.6 & .352 \\
\hline Evenings & 96 & 163020 & 1.1 & 65 & 73292 & 1.1 & 0.0 & .952 \\
\hline Early morning & 159 & 233926 & 1.1 & 2 & 2387 & .9 & .4 & .774 \\
\hline All day & 153 & 222755 & 1.1 & 8 & 13558 & 3.8 & 62.1 & ** \\
\hline \multicolumn{9}{|l|}{ Who do you prefer to gamble with $?^{2}$} \\
\hline Partner (spouse/boy/girlfriend) & & & & 3 & 6686 & .8 & 218.4 & $* * *$ \\
\hline Relatives & & & & 30 & 31092 & .5 & & \\
\hline Acquaintances & & & & 9 & 6105 & .6 & & \\
\hline Strangers & & & & 6 & 9721 & 3.7 & & \\
\hline Alone & & & & 17 & 24170 & .6 & & \\
\hline
\end{tabular}

Note: The population analyzed has bet at lifetime $(N=20864589, n=13115)$. The $N$ with gambling disorder (four or more symptoms) was $N=$ 236 313. ${ }^{1}$ Respondents could choose more than one schedule option; ${ }^{2}$ The comparison involves the proportion of gambling disorder between each category of the persons whom respondents prefer to gamble with.

${ }^{*} p<.05 ;{ }^{* *} p<.01 ;{ }^{* * *} p<.001$.

the highest preference for them $(26.6 \%)$. It is important to note that betting machines or slot machines are not allowed in Mexico. Moreover, the Secretaría de Gobernación (2018) regards them as a great risk to society, since they can cause rapid addiction to gambling, due to the false expectation of earning easy money. It also considers them a source of corruption of minors, particularly adolescents, who are at a greater risk of developing gambling problems than adults (Becoña, Míguez, \& Vázquez, 2001).

It was found that men engage most in the various types of games except for bingo. In this ratio between men and women, it is interesting that, in bets that involve playing in a casino, the Lottery or Melate, slot machines, and instant draws, this proportion is lower than in other betting types.

On the other hand, although adults were expected to play more, the results show that, in general terms, the highest prevalence was found in the young population ages 18 to 29 , which is consistent with the results obtained in other studies (Huang \& Boyer, 2007; Cruz et al., 2010; Forrest \& McHale, 2012; Ekholm et al., 2014; Sarti \& Triventi, 2017).

It is also observed that those with a higher socioeconomic index use more diverse betting types, particularly playing dice and betting in a casino, probably as a result of their greater purchasing power (Welte, Barnes, Wieczorek, Tidwell, \& Parker, 2002; Welte, Barnes, Wieczorek, Tidwell, \& Hoffman, 2011).

\section{Magnitude and extent of gambling disorder}

A quarter of the Mexican population aged between 12 and 65 years has bet money at lifetime, and .3\% present gambling disorder, equivalent to just over 230000 people. This prevalence of dependence on gambling is low, which represents an opportunity to work more on prevention. Moreover, they are located in the lowest part of the range obtained in studies from various countries (from .1\% to 2.2\%) (Bakken et al., 2009; Tavares et al., 2010; Goudriaan, 2013; Calado \& Griffiths, 2016; Gambling Commission, 2018).

Of the nine symptoms of gambling disorder, men had higher prevalences than women in six. Likewise, although gambling behaviors occurred more frequently at older ages, adolescents presented greater symptomatology and presence of gambling disorder in comparison with the adult population ages 30 to 65 (.4\% vs. .2\%, respectively), which has also been observed in previous studies (Huang \& Boyer, 2007; Ekholm et al., 2014; Giacaman et al., 2015; Husky, Michel, Richard, Guignard, \& Beck, 2015; Sherba \& Martt, 2015). Research has shown that when individuals begin gambling at an early age, their behavior can become more severe in the adult stage and facilitate the development of gambling disorder and other problems related to gambling (Angulo, 2014; Browne et al., 2016).

An important variable for becoming involved in betting is the search for new sensation, a characteristic feature of adolescence, which can lead them to engage in various risk behaviors (Angulo, 2014). Preventive intervention in this age group is therefore essential, both in providing psychoeducational information on the consequences of short-, medium-, and long-term gambling, and in supporting them in the development of socio-emotional skills. These skills allow them, on the one hand, to cope with the various difficulties they experience at this stage of their lives and, on the other, to strengthen their emotional stability (Afifi et al., 2010; Castaño et al., 2016).

\section{Betting types and gambling disorder}

Although the prevalences of gambling dependence or gambling disorder are low, it was observed that the betting pop- 
ulation, who bet on horses, dice, skill games, and online, or go to a casino, have higher percentages of approximately $3.3 \%$. Something similar occurs with those who report gambling all day or who bet with strangers. These are precisely the elements that must be constantly monitored among the population that engages in betting to prevent their playing from becoming a mental health concern that affects their health and environment.

Likewise, these findings should prompt the analysis and monitoring of the availability of gambling places, tolerance, and acceptance of betting behaviors by the community and family, since they can facilitate the triggering of a problem gambling pattern (Hanss et al., 2015; Welte et al., 2017), and affect both family relationships and those with one's peer group (Castaño et al., 2016).

In this context, analyzing the availability of betting places is important for Mexico, since 27 of the country's 32 states have authorized concessions for operating casinos and betting games. Sonora, Jalisco, and Baja California are states with more than 30 establishments each (Secretaría de Gobernación, 2018), not counting clandestine betting places.

The data presented here are important for determining the magnitude of the problem of gambling disorder, as well as its relationship with various sociodemographic variables. Nevertheless, it is important to have an in-depth knowledge of the social, interpersonal, and personal variables related to this behavior. When analyzing the limitations of this study, it is important to consider that the low prevalence found makes it impossible to obtain a large sample of people with gambling disorder to evaluate other important factors related to the topic and map the states in which this problem is most present.

Likewise, although the instrument used in this study is based on the symptoms described in the DSM-IV and DSM-5 (which allows for comparison with other studies using these indicators) and has adequate reliability, it is important to undertake a clinical study that evaluates its sensitivity and specificity in order to more accurately gauge evaluations of this nature.

Lastly, studies on this issue must continue in order to make it possible to intervene in time and provide guidelines for better prevention actions in adolescents, a group with a higher prevalence of gambling disorder.

\section{Funding}

The 2016-2017 ENCODAT survey was financed by the Comisión Nacional Contra las Adicciones (CONADIC), while the development of the analysis and preparation of reports was financed by the US Department of State through the INL offices with the SINLEC17CA2011 project number as part of the Mérida Initiative.

\section{Conflict of interests}

The authors declare that they have no conflict of interests.

\section{Acknowledgements}

We would like to thank Diana Anahí Fregoso Ito for her support at the beginning of this study.

\section{REFERENCES}

Afifi, T., Cox, B., Martens, P., Sareen, J., \& Enns, M. (2010). Demographic and social variables associated with problem gambling among men and women in Canada. Psychiatry Research, 178(2), 395-400.

American Psychiatric Association. (1980). DSM-III. Manual diagnóstico y estadístico de los trastornos mentales. Barcelona: Masson.

American Psychiatric Association. (2014). Manual diagnóstico y estadístico de los trastornos mentales DSM-5. Bogotá: Panamericana.

Angulo, A. (2014). Rasgos de personalidad como variables mediadoras en la edad de inicio del juego patológico y su severidad. Universitat Autònoma de Barcelona, Personality traits and pathological gambling.

Arcaya, M., Martina, M., Gutiérrez, C., \& Romero, Y. (2012). Práctica de juegos de azar y su relación con la integración familiar en la población peruana. Revista Peruana de Epidemiología, 16(1), 1-7.

Bakken, I. J., Götestam, K. G., Gråwe, R. W., Wenzel, H. G. \& Øren, A. (2009). Gambling behavior and gambling problems in Norway 2007. Scandinavian Journal of Psychology, 50(4), 333-339.

Becoña, E., Míguez, M. C., \& Vázquez, F. L. (2001). El juego problema en los estudiantes de Enseñanza Secundaria. Psicothema, 13(4), 551-556.

Browne, M., Langham, E., Rawat, V., Greer, N., Li, E., Rose, J., ... Best, T. (2016). Assesing gambling-related harm in Victoria: a public health perspective. Melbourne: Victorian Responsible Gambling Foundation.

Calado, F. \& Griffiths, M. D. (2016) Problem gambling worldwide: An update and systematic review of empirical research (2000-2015). Journal of Behavioral Addictions, 5(4), 592-613.

Castaño, G. A., Calderón, G. A., \& Restrepo, S. M. (2016). Factores de riesgo para ludopatía en un grupo de jugadores de casinos de la ciudad de Medellín, Colombia. Health and Addictions, 16(2), 135-145.

Comisión Nacional contra las Adicciones. (2012). Consideraciones generales hacia la prevención y la atención del juego patológico en México. Ciudad de México: Secretaría de Salud.

Cruz, A., Argeñal, A., Padilla, C., George, E., Novondo, E. B. F., Padilla, G., ... Núñez, R. C. (2010). Ludopatía: Características de la población que asiste a salas de juego en Tegucigalpa. Revista de la Facultad de Ciencias Médicas, 27-37.

Díaz-Acosta, R., Shiba-Matsumoto, A. R. \& Gutiérrez, J. P. (2015). Medición simplificada del nivel socioeconómico en encuestas breves: propuesta a partir de acceso a bienes y servicios. Salud Pública de México, 57(4), 298-303.

Domínguez, A. M. (2009). Epidemiología y factores implicados en el juego patológico. Apuntes de Psicología, 27(1), 3-20.

Ekholm, O., Eiberg, S., Davidsen, M., Holst, M., Larsen, C. V., \& Juel, K. (2014). The prevalence of problem gambling in Denmark in 2005 and 2010: a sociodemographic and socioeconomic characterization. Journal of Gambling Studies, $30(1), 1-10$.

Forrest, D. \& McHale, I. G. (2012). Gambling and problem gambling among young adolescents in Great Britain. Journal of Gambling Studies, 28(4), 607-622.

Gambling Commission. (2018). Gambling participation in 2017: behavior, awareness and attitudes Annual Report. United Kingdom.

Giacaman, I., Ñancupil, W., \& Jobet, J. (2015). Estimated Prevalence of Pathological Gambling among college students of the Universidad Austral de Chile, Valdivia, 2013. Revista ANACEM, 9(2), 58-61.

Goudriaan, A. E. (2013). Gambling and problema gambling in the Netherlands. Addiction, 109(7), 1066-1071.

Hanss, D., Mentzoni, R., Blaszczynski, A., Molde, H., Torsheim, T., \& Pallesen, S. (2015). Prevalence and Correlates of Problem Gambling in a Representative Sample of Norwegian 17-Year-Olds. Journal of Gambling Studies, 31(3), 659-678.

Hodgins, D. C., Schopflocher, D. P., Martin, C. R., El-Guebaly, N., Casey, D. M., Currie, S. R., ... Williams, R. J. (2012). Disordered gambling among higher-frequency gamblers: who is at risk?. Psychological Medicine, 42(11), 2433-2444. 
Huang, J.-H. \& Boyer, R. (2007). Epidemiology of Youth Gambling Problems in Canada: A National Prevalence Study. The Canadian Journal of Psychiatry, 52(10), 657-665

Husky, M. M., Michel, G., Richard, J. B., Guignard, R., \& Beck, F. (2015). Gender differences in the associations of gambling activities and suicidal behaviors with problem gambling in a nationally representative French sample. Addictive Behaviors, 45, 45-50. doi: 10.1016/j.addbeh.2015.01.011

Ortega, P., Vázquez, B., \& Reidl, L. (2009). Ludopatía. Biblioteca Jurídica Virtual del Instituto de Investigaciones Jurídicas de la UNAM. Retrieved from: https:// archivos.juridicas.unam.mx/www/bjv/libros/6/2803/13.pdf

Potenza, M. N. (2008). The neurobiology of pathological gambling and drug addiction: An overview and new findings. Philosophical Transactions of the Royal Society of London B: Biological Sciences, 363(1507), 3181-3189.

Sarti, S. \& Triventi, M. (2017). The role of social and cognitive factors in individual gambling: An empirical study on college students. Social Science Research, 62, 219-237.

Secretaría de Gobernación. (2018). Salas de Sorteos de Números y Centros de Apuestas Remotas. Ciudad de México: Dirección General de Juegos y Sorteos. Retrieved from: http://www.juegosysorteos.gob.mx/en/Juegos_y_Sorteos/ Salas de Sorteos de Numeros

Santos, J. A. (2008). Manual de intervención en juego patológico. Cáceres: Junta de Extremadura.
Sherba, R. T. \& Martt, N. J. (2015). Overall gambling behaviors and gambling treatment needs among a statewide sample of drug treatment clients in Ohio. Journal of Gambling Studies, 31(1), 281-293.

Tavares, H., Carneiro, E., Sanches, M., Pinsky, I., Caetano, R., Zaleski, M., \& Laranjeira, R. (2010). Gambling in Brazil: lifetime prevalences and socio-demographic correlates. Psychiatry Research, 180(1), 35-41.

Villatoro, J. A., Resendiz, E., Mujica, A., Bretón, M., Cañas, V., Soto, I., \& Mendoza, L. (2017). Encuesta Nacional de Consumo de Drogas, Alcohol y Tabaco 20162017: Reporte de Drogas. Ciudad de México: Instituto Nacional de Psiquiatría Ramón de la Fuente Muñiz. Retrieved from: www.conadic.gob.mx

Welte, J., Barnes, G., Wieczorek, W., Tidwell, M. C. \& Parker, J. (2002). Gambling Participation in the U. S. - Results from a National Survey. Journal of Gambling Studies, 18(4), 313-337.

Welte, J., Barnes, G., Wieczorek, W., Tidwell, M. C. \& Hoffman, J. (2011). Gambling and Problema Across the Lifespan. Journal of Gambling Studies, 27(1), 49-61.

Welte, J., Barnes, G., Tidwell, M. C., \& Wieczorek, W. (2017). Predictors of Problem Gambling in the U.S. Journal of Gambling Studies, 33(2), 327-342.

World Health Organization. (2004) ¡. ICD-10: International Statistical Classification of Diseases and Related Health Problems: Tenth Revision. Geneva: World Health Organization. 